\title{
The Case for Changing the Narrative in Health \& Social Care
}

\author{
Prof Parag Singhal, MD, MPhil, FRCP, FACP \\ Organising Chair, Hon Secretary BAPIO, Chair BAPIO South West \\ Contribution from Anand Kumar
}

cite as: Singhal, P. (2018) The case for changing the narrative in health and social care. Sushruta Oct 11(1):13-14 DOI: 10.38192/11.1.4

Given our current challenges, how can we contribute to make a difference to patient care and service efficiencies? In other words, how can we all work towards changing the narrative and acting in different ways to make a difference to our patients, colleagues and organisations alike. Whilst not overstating the case, our NHS is being challenged from several angles. Many colleagues are under serious work pressures, are stressed, suffer with low morale, some are voting with their feet and many more are reporting burnout. And yes, some of our patients are not having the timely care that they deserve? Many of our organisations are in financial distress; many are in special measures and Turnaround Regimes.

The pressure points are being reported from several sources. For instance The Royal College of Physicians (2017) Survey Report NHS reality check: Delivering care under pressure involving 2,100 Doctors indicated that:

- $78 \%$ say demand for their service is rising.

- Over half of physicians believe patient safety has deteriorated.

- Over a third say the quality of care has lowered.

- $84 \%$ have reported staffing shortages in their team.

- $82 \%$ believe the workforce is demoralised.

Prof Jane Dacre, President of the RCP, commented 'I am sure these figures will not come as a surprise to anyone in the room. The physicians I know, and I include myself, are optimistic, positive, can-do people who produce 'work round' solutions to intransigent problems. However, they are being pushed to their limits and no longer are optimistic about the future." Similarly the Guardian [11 Feb 2017] reported on a survey of 2,300 trainee anaesthetists and found that "six out of seven - $85 \%$ - are at risk of becoming burned out, despite only being in their 20s and 30s. Respondents identified long hours, fears about patient safety, the disruption of working night shifts and long commutes to their hospital as key reasons for their growing fatigue and disillusionment."

No doubt you will be able to point to similar findings or reports or know of colleagues with similar experiences. But here is the good news. Yes, we are pressured and face many challenges, but we are not and should not be helpless. Several commentators have argue that staff at the front line know the solutions. I believe the time is right for us all to play our part in 
helping to change the narrative and as a consequence act differently. It is time that we build on the massive good will of most of our colleagues and it is time to liberate energies and mobilise collectively to add value.

So what do I mean by narrative? Collins English Dictionary defines narrative as a 'story or account of a series of events." All of us and leaders at different levels need to change the narrative by sharing stories that can engage and mobilise others to action. Steve Denning is a leadership thought leader, author and guru. A short while ago, a colleague asked him why leadership story telling was important. He came up with a long list. I am including 2 accounts here.

Story telling is a key leadership technique because it's quick, powerful, free, natural, refreshing, energising, collaborative, persuasive, holistic, entertaining, moving, memorable and authentic. Stories help us make sense of organisations. Story telling can inspire people to act in unfamiliar, and often unwelcome, ways. Mind-numbing cascades of numbers or daze-inducing PowerPoint slides won't achieve this goal. Even logical arguments for making the needed changes usually won't do the trick but creative story telling does. We know that there are different types of stories and Steve Denning has shown how stories can:

1. Spark action (the original springboard story)

2. Communicate who we are (identity stories)

3. Communicate who the company is (corporate identity and branding)

4. Proclaim and transmit values (value stories)

5. Foster collaboration (community-building stories)

6. Tame the grapevine (political stories)

7. Share knowledge (tacit knowledge stories)

8. Lead people into the future (inspirational and vision stories)

Similarly, Dr Helen Bevan, Chief Transformation Officer at Horizons NHS has been at the forefront of promoting the work of Prof Marshall Ganz from Harvard whose work on the power of stories for creating change and mobilising for action offers great potential in the NHS. Prof Ganz has argued that "Stories not only teach us how to act - they inspire us to act. Stories communicate our values through the language of the heart, our emotions. And it is what we feel - our hopes, our cares, our obligations - not simply what we know that can inspire us with the courage to act."

Prof Ganz has proposed that a public story includes three elements as follows:

- A story of self: why you were called to what you have been called to.

- A story of us: what your constituency, community, organisation has been called to its shared purposes, goals, vision.

- A story of now: the challenge this community now faces, the choices it must make, and the hope to which "we" can aspire. 
Story telling from board level all the way down to the front line is vital at engaging and mobilising all of our people for sustaining action that can bring about a better patient and staff orientated NHS. They can serve to develop better collaboration within and across organisations as well as laying the basis for delivering on effectiveness and productivity. It can help to create a work climate that enables us to be more caring, supportive and compassionate to our colleagues.

\section{Some encouraging signs:}

The good news is that there are some encouraging signs in which Clinicians, Leaders and Managers are stepping up at taking a lead on changing the narrative. Writing in BMJ (BMJ 2017;359:j4304), Dr David Oliver has argued why it is useful for Challenging the victim narrative about NHS doctors. Despite the challenges being faced, he has suggested that doctors "are not hapless victims. We have to be realistic as to what we can achieve. We must also use our considerable hard power, soft influence and status to the best effect to preserve and improve patient care."

On similar lines, a recent tweet from Mr Ross Fisher, a paediatric surgeon at Sheffield Children's Hospital, "I'm the Consultant on call today. I gathered the whole team together and reiterated that we work as a team, that mine is the ultimate responsibility, that if they have concerns they escalate and NO-ONE gets thrown under the bus. These are the kinds of narratives and stories that lead to action, which needs no one's permission. Imagine then the work place culture if more and more Consultants were to take a lead from Mr Fisher's example?

2018 marks the 70th anniversary of the establishment of the NHS. It is a time to celebrate the wondrous achievements of the service. It is also a time to make a Call to Action, given our challenges, to invite everyone to play their part in the making of a sustainable NHS. Our starting point is to change the narrative to build a better NHS for patients and staff.

Bibliography

https://www.rcplondon.ac.uk/projects/outputs/nhs-reality-check-2017-delivering-careunder-pressure https://www.theguardian.com/uk-news/2017/feb/11/stressed-out-doctors-anaesthetistssurvey-nhs https://www.bmj.com/content/359/bmj.j4304 